Swarthmore College

Works

7-1-1992

\title{
Differential Expression Of Gap Junction mRNAs And Proteins In The Developing Murine Kidney And In Experimentally Induced Nephric Mesenchymes
}

\author{
K. Sainio \\ Scott F. Gilbert \\ Swarthmore College, sgilber1@swarthmore.edu \\ E. Lehtonen \\ M. Nishi \\ N. M. Kumar
}

See next page for additional authors

Follow this and additional works at: https://works.swarthmore.edu/fac-biology

Part of the Biology Commons

Let us know how access to these works benefits you

\section{Recommended Citation}

K. Sainio, Scott F. Gilbert, E. Lehtonen, M. Nishi, N. M. Kumar, N. B. Gilula, and L. Saxen. (1992).

"Differential Expression Of Gap Junction mRNAs And Proteins In The Developing Murine Kidney And In Experimentally Induced Nephric Mesenchymes". Development. Volume 115, Issue 3. 827-837.

https://works.swarthmore.edu/fac-biology/206

This work is brought to you for free by Swarthmore College Libraries' Works. It has been accepted for inclusion in Biology Faculty Works by an authorized administrator of Works. For more information, please contact myworks@swarthmore.edu. 
Authors

K. Sainio, Scott F. Gilbert, E. Lehtonen, M. Nishi, N. M. Kumar, N. B. Gilula, and L. Saxen 


\title{
Differential expression of gap junction mRNAs and proteins in the developing murine kidney and in experimentally induced nephric
} mesenchymes

\author{
KIRSI SAINIO ${ }^{1}$, SCOTT F. GILBERT ${ }^{1,2}$, EERO LEHTONEN ${ }^{1}$, MIYUKI NISHP ${ }^{3}$, NALIN M. KUMAR ${ }^{3}$, NORTON B. \\ GILULA $^{3}$ andLAURI SAXÉN ${ }^{1, *}$ \\ ${ }^{1}$ Department of Pathology, University of Helsinki, Haartmaninkatu 3, SF-00290 Helsinki, Finland \\ ${ }^{2}$ Department of Biology, Swarthmore College, Swarthmore, Pennsylvania 19081-1397, USA \\ ${ }^{3}$ Department of Cell Biology, The Scripps Research Institute, 10666 North Torrey Pines Road, La Jolla, California 92037, USA \\ *Corresponding author
}

\section{Summary}

The expression of three gap junction (GJ) proteins, $\alpha_{1}$ $(\mathbf{C x} 43), \beta_{1}(\mathrm{Cx} 32)$, and $\beta_{2}(\mathrm{Cx} 26)$, and their transcripts were examined during the ontogeny of the mouse and rat kidney. These proteins were expressed in two non-overlapping patterns. The $\alpha_{1}$ GJ protein was first observed in mesenchymal cells in the 12-day mouse kidney. By day 14 and thereafter, the $\alpha_{1}$ protein was detected in the transient S-shaped bodies, but not in the podocytes of the maturing glomeruli. After birth the antigen was retained in a small subset of secretory tubules.

The $\beta_{1}$ and $\beta_{2}$ GJ proteins were similar in their developmental patterns. They were first detected in a small subset of secretory tubules in the subcortical zone of day 17 embryos. These tubules were identified by immunohistochemical markers to be proximal. At birth, practically all proximal tubules expressed the two antigens.

This analysis of GJ proteins was consistent with the results of $\mathrm{S} 1$ nuclease protection assays showing that, while the $\alpha_{1}$ mRNA appeared early during kidney development and declined around birth, the two $\beta$ mRNAs appeared later and became intensified during the last days of intrauterine development.
In experimentally induced metanephric mesenchymes, a transient expression of the $\alpha_{1}$ GJ protein was seen during the segregation of the tubular anlagen. $\beta_{1}$ and $\beta_{2}$ GJ proteins were not detected in such induced mesenchymes cultivated up to 7 days.

These observations provide evidence for the cellspecific utilization of different GJ genes during different stages of kidney organogenesis. The $\alpha_{1}$ gene is activated during the early segregation of the secretory tubule and might contribute to its compartmentalization, while the $\beta_{1}$ and $\beta_{2}$ gene products are not detected until advanced stages of development. The latter gene products might be correlated with the physiological activity of the proximal tubules in vivo, as they are not expressed in experimentally induced tubules detectable with markers for proximal tubules.

Key words: murine embryo, gap junctions, mRNA, protein, kidney differentiation, metanephric mesenchyme, transfilter induction.

\section{Introduction}

Gap junctions contain transmembrane channels that directly link adjacent cells and provide pathways for the transfer of low molecular weight molecules and ions from one cell to another (Gilula et al., 1972; Bennett and Goodenough, 1978; Loewenstein, 1981). The junctional channels are bipartite structures formed by the association of two oligomeric structures or connexons, each connexon representing an oligomeric arrangement of six polypeptides. The gap junction (GJ) proteins have been derived from a multigene fam- ily, based on a conserved region of about 200 amino-terminal residues that includes four transmembrane and two extracellular domains (Zimmer et al., 1987; Beyer et al., 1987; Milks et al., 1988; Goodenough et al., 1988; Nicholson and Zhang, 1988; Hertzberg et al., 1988; Yancey et al., 1989). Fulllength sequences for several of these proteins have been deduced from cDNA analysis: a $32 \times 10^{3} M_{\text {r }}$ protein from mammalian liver (Paul, 1986; Kumar and Gilula, 1986), a 43 $\times 10^{3} M_{\mathrm{r}}$ protein from mammalian heart (Beyer et al., 1987), a $26 \times 10^{3} M_{\mathrm{r}}$ protein from mammalian liver (Nicholson and Zhang, 1988), and a $31 \times 10^{3} M_{\text {r }}$ protein from several mam- 
malian tissues, including placenta and skin (Hoh et al., 1991). A $46 \times 10^{3} M_{\mathrm{r}}$ protein found in the lens also appears to be a member of this family because of its predicted structural motif (Kistler et al., 1988; Beyer et al., 1989). On the basis of predicted structural similarities, the multigene family has been divided into two classes, $\alpha$ and $\beta$ (Risek et al., 1990). The $\alpha$ class contains $\alpha_{1}\left(43 \times 10^{3} M_{\mathrm{r}}\right), \alpha_{2}\left(38 \times 10^{3} M_{\mathrm{r}}\right.$ from amphibians) and $\alpha_{3}\left(46 \times 10^{3} M_{\mathrm{r}}\right)$; while the $\beta$ class contains $\beta_{1}\left(32 \times 10^{3} M_{\mathrm{r}}\right), \beta_{2}\left(26 \times 10^{3} M_{\mathrm{r}}\right)$ and $\beta_{3}\left(31 \times 10^{3} M_{\mathrm{r}}\right)$.

Gap junctions mediate important developmental and physiological activities. In excitable tissues, gap junctions provide low-resistance coupling pathways for nerve conductance (Furshpan and Potter, 1968), myocardial contraction (Dreifuss et al., 1966) and the coordination of smooth muscle movement (for review, see Daniel, 1987). The specific function of each type of GJ protein remains largely unknown, although the dramatic elevation of $\alpha_{1}$ mRNA seen in the myometrium the day before parturition is thought to be responsible for producing the junctions that synchronize the uterine contractions (Risek et al., 1990). During development, gap junctions have been shown to play important roles in compartmentalizing cells and in transmitting morphogenetic information (for review, see Guthrie and Gilula, 1989). Gap junctions connect the blastomeres of the 8-cell mouse embryo (Lo and Gilula, 1979) and, if junctional communication between cells of these embryos is blocked by treatment with antibodies that bind to GJ proteins, the communication-deficient cells are not retained by the compacted embryo (Lee et al.,1987). Drosophila imaginal discs and the gastrulating mouse embryo are both divided into communication compartments by GJ pathways that exist between certain cells and not others (Weir and Lo, 1982; Kalimi and Lo, 1988, 1989). Gap junctions also form communication compartments in developing frog embryos, which physiologically separate the presumptive neural ectoderm from presumptive epidermis (Warner, 1973). When antibodies to mammalian GJ protein were injected into blastomeres of 8cell Xenopus embryos, electrical and ionic coupling was inhibited, and patterning defects (asymmetries) developed in those regions derived from the injected blastomere (Warner et al., 1984). Information transfer through gap junctions has also been found in developing invertebrates. The gradient of hydra head inhibitor was blocked by treatment with antibodies to mammalian GJ proteins (Fraser et al., 1987), and gap junctions appear at the specific time when the information required to form molluscan mesoderm is activated in the 3D macromere by contact with vegetal micromeres (de Laat et al., 1980).

The mammalian kidney provides an opportunity to analyze whether three of the well-characterized GJ proteins $\left(\alpha_{1}, \beta_{1}\right.$ and $\left.\beta_{2}\right)$ are utilized differentially during organ development. The kidney develops as a result of interactions between two tissues, the ureter bud and the metanephrogenic mesenchyme (reviewed in Saxén, 1987). When the bud enters the mesenchymal blastema on day 11 of mouse development, the mesenchymal cells induce it to branch. Conversely, the epithelium induces the mesenchyme to form the secretory nephrons first visualized as condensations around the tips of the ureter. The condensed cells then form a renal vesicle which develops a central cavity, and, subsequently, an S-shaped body is formed. The portion of this tube closest to the ureter becomes the distal tubule cells, while the rest develops into proximal tubules and the epithelium of the glomerulus. The continuous branching of the ureter bud and its induction of nephron formation in the mesenchyme generate the metanephric kidney.

Using antibodies and cDNA probes to three GJ proteins and their messengers, we analyzed the spatial and temporal distribution of these GJ proteins during mouse renal development. Results from this study demonstrate that the expression of these GJ proteins correlates with specific cell types.

\section{Materials and methods}

\section{RNA analysis}

Embryonic kidneys at different developmental stages were obtained by timed matings of Balb/c $\times \mathrm{C} 57 \mathrm{BL} / 6 \mathrm{~F}_{1}$ mice. The appearance of the vaginal plug was noted as day 0 . The embryonic kidneys were removed at appropriate post-implantation stages in order to prepare RNA for analysis. For extraction of total RNA from the kidney samples, an acid phenol-guanidinium thiocyanate procedure was applied with RNAzol (Cinna/Biotex). The extracted RNA from the different stages was analyzed by using a mixture of GJ probes (for $\alpha_{1}, \beta_{1}$ and $\beta_{2}$ ) in an $\mathrm{S} 1$ nuclease protection assay as described previously (Davis et al., 1986; Nishi et al., 1991).

\section{Histology}

The kidneys were fixed with $2.5 \%$ glutaraldehyde in $0.1 \mathrm{M}$ phos-

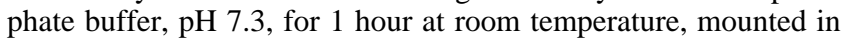
Epon, and $1 \mu \mathrm{m}$ sections were cut for staining with toluidine blue and examined in light microscopy.

\section{Immunohistochemistry}

Sections from whole embryonic kidneys, transfilter explants and reaggregated mesenchymal cell cultures were analyzed by immunohistochemistry. Affinity-purified rabbit antibodies were prepared against synthetic peptides corresponding to the $S$ epitopes of GJ proteins $\alpha_{1}$ and $\beta_{1}$ and the J epitope of $\beta_{2}$ (Milks et al., 1988; Risek et al., 1990). Mouse embryos from matings of CBA males with NMRI females and Spraque-Dowley rat embryos, used for doublestaining immunofluorescence experiments, were obtained from the breeding colony of the Department of Pathology, University of Helsinki. For indirect immunohistochemistry, whole embryonic kidneys were rapidly frozen in OCT and sectioned on a Leitz 1720 cryostat without prior fixation. Sections of 5-6 $\mu \mathrm{m}$ were incubated with 3\% BSA, 3\% goat serum (Vector Laboratories, Burlingame, $\mathrm{CA})$ in PBS (10 mM sodium phosphate, $\mathrm{pH} 7.5,0.9 \% \mathrm{NaCl})$ for 1 hour at room temperature to reduce non-specific binding. Incubation with preimmune serum or antibodies was performed overnight at $4^{\circ} \mathrm{C}$ in the BSA- and goat serum-containing buffer, followed by three washes in PBS. FITC- and TRITC-conjugated donkey antirabbit IgG (Jackson ImmunoResearch, West Grove, PA) diluted 1:200 in PBS was added to the slides for 1 hour at room temperature. The slides were then washed three times in PBS and mounted in PBS-containing glycerol or in Elvanol (Klein et al., 1988). Podocalyxin, a rat podocyte- and endothelium-specific antibody (Schnabel et al., 1989, Miettinen et al., 1990), dipeptidylpeptidase IV, a rat proximal-tubule-specific antibody (Miettinen et al., 1990), as well as brush border and Tamm-Horsfall glycoprotein antibodies (Miettinen and Linder, 1976; Sikri et al., 1979; Dawnay et al., 1980; Ekblom et al., 1980) were generous gifts of Dr A. Miettinen (Department of Bacteriology and Immunology, University of 
Helsinki). Double-staining immunofluorescence also utilized TRITC-conjugated goat anti-mouse IgG (Jackson ImmunoResearch) diluted 1:100 and FITC-conjugated goat anti-rat IgG (Cappel Laboratory, Cochranville, PA) diluted 1:500. Immunofluorescence was analyzed using a Zeiss Axiophot microscope with epifluorescence. Photographs were taken with Fuji Neopan 1600 ASA black-and-white professional print film.

Confocal microscopy was performed with the confocal scanning laser beam fluorescence microscope developed at the European Molecular Biology Laboratories, Heidelberg. The design and operating principles of this microscope have been described previously (Bacallao et al., 1989; Stelzer et al., 1989). FITC was excited at 488 $\mathrm{nm}$ by an argon laser (2020-05 SpectraPhysics, Inc., Mountain View, CA), and serial optical sections were made at $0.3-\mu \mathrm{m}$ or 0.5 $\mu \mathrm{m}$ intervals.

\section{Transfilter induction}

Metanephric kidney rudiments were dissected from 11-day mouse and 13-day rat embryos. To separate the mesenchyme from the epithelial ureter bud, the explants were incubated in $0.75 \%$ pancreatin- $2.25 \%$ trypsin for 1.5 minutes at $0^{\circ} \mathrm{C}$. The manual separation was performed under a stereomicroscope at room temperature in Eagle's Minimum Essential Medium (MEM) supplemented with $10 \%$ fetal calf serum (FCS; Myoclone Plus, GIBCO, Paisley, Scotland). Fragments of spinal cord from the same embryos were used as inducers in the transfilter experiments (Saxén and Lehtonen, 1978). In some experiments, the transfilter contact was interrupted after 22 hours and 48 hours to follow the development of the mesenchyme in prolonged cultures after a short induction pulse.

The isolated mesenchymes were transferred onto Nuclepore filters (General Electron Co., Pleasanton, CA) with an average pore size of $1.0 \mu \mathrm{m}$. A piece of spinal cord was glued beforehand on the opposite side of the filter, using agarose (Grobstein, 1956; Saxén and Lehtonen, 1987). The transfilter explants were cultured in MEM with $10 \%$ FCS and harvested at different intervals for immunohistochemistry.

\section{Results}

\section{Temporal analysis of GJ mRNA expression during kidney} development

The expression of GJ mRNA from three genes $\left(\alpha_{1}, \beta_{1}, \beta_{2}\right)$ during kidney development was studied by applying an $\mathrm{S} 1$ nuclease protection assay to RNA that was isolated at different developmental stages.

For this analysis, probes for all three transcripts were added together so that all three products could be analyzed simultaneously (Fig. 1). In the 13-day mouse embryonic kidney, the $\alpha_{1}$ transcript was seen to be present at high levels. These levels remained high throughout development, but declined around birth. The $\beta_{1}$ transcript was readily detected by day 15 , and the expression of this mRNA increased throughout development. On day 17, transcription of the $\beta_{2}$ message was detected, and the accumulation of this transcript increased dramatically after birth. The overall developmental pattern of expression differed for $\alpha_{1}$ versus $\beta_{1}$ and $\beta_{2}$. The $\alpha_{1}$ transcript was expressed at high abundance during early development, but the expression decreased significantly after birth. Conversely, the expression of the $\beta_{1}$ and $\beta_{2}$ transcripts increased significantly during development and after birth.

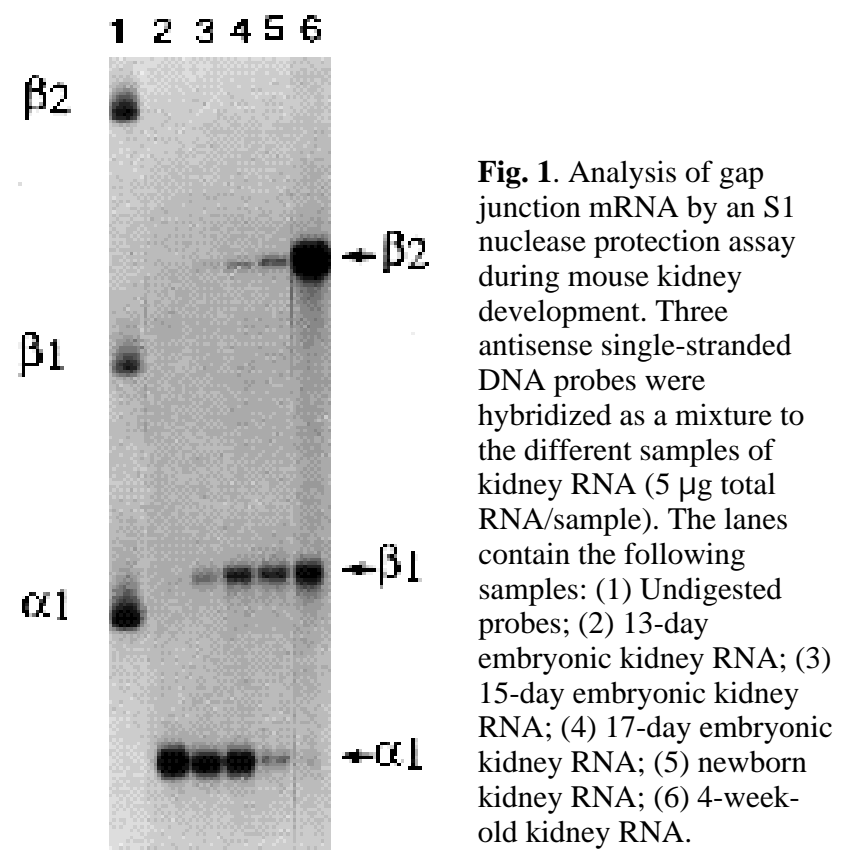

In summary, the data from this analysis provides evidence that all three GJ genes are expressed during the development of the kidney, that these genes are developmentally regulated, and that there is a change in the relative abundance of these transcripts during kidney organogenesis.

\section{Spatial and temporal immunolocalization of GJ proteins in the developing kidney}

Expression pattern of the $\alpha_{1} G J$ protein

Stages of the early development of the metanephric kidney are illustrated in Fig. 2.

By immunohistochemistry, the $\alpha_{1}$ GJ protein was detectable in the 12-day embryo. At this early stage of kidney development, the ureteric bud has branched only two or three times and patches of immunofluorescence were observed in the mesenchyme near these branches. This immunofluorescence in the mesenchyme was not seen in samples stained with preimmune sera or with the antibodies for other GJ proteins. By day 14, the expression of $\alpha_{1}$ was localized to a particular subset of kidney mesenchymal cells: it was detected only on the cells that had formed the S-shaped bodies. The cells expressing $\alpha_{1}$ in the 14-day mouse kidney were predominantly found in a subcortical zone containing early Sshaped bodies (Fig. 3A). Higher magnification of one of these regions (Fig. 3B) shows the relationship between the ureter bud and the $\mathrm{S}$-shaped bodies on either side of it. The highest staining intensity of the $\alpha_{1}$ antigen was in the crevice furthest from the ureter-derived collecting duct. The epithelial cells of this region are the presumptive glomerular podocytes, but when they mature, the $\alpha_{1}$ antigen is concomitantly downregulated; double immunostaining with $\alpha_{1}$ antibody and antipodocalyxin reveals no overlapping (Fig. 3CF).

\section{Expression pattern of the $\beta_{2}$ GJ protein}

The $\beta_{2}$ GJ protein could not be detected until around day 17 . 

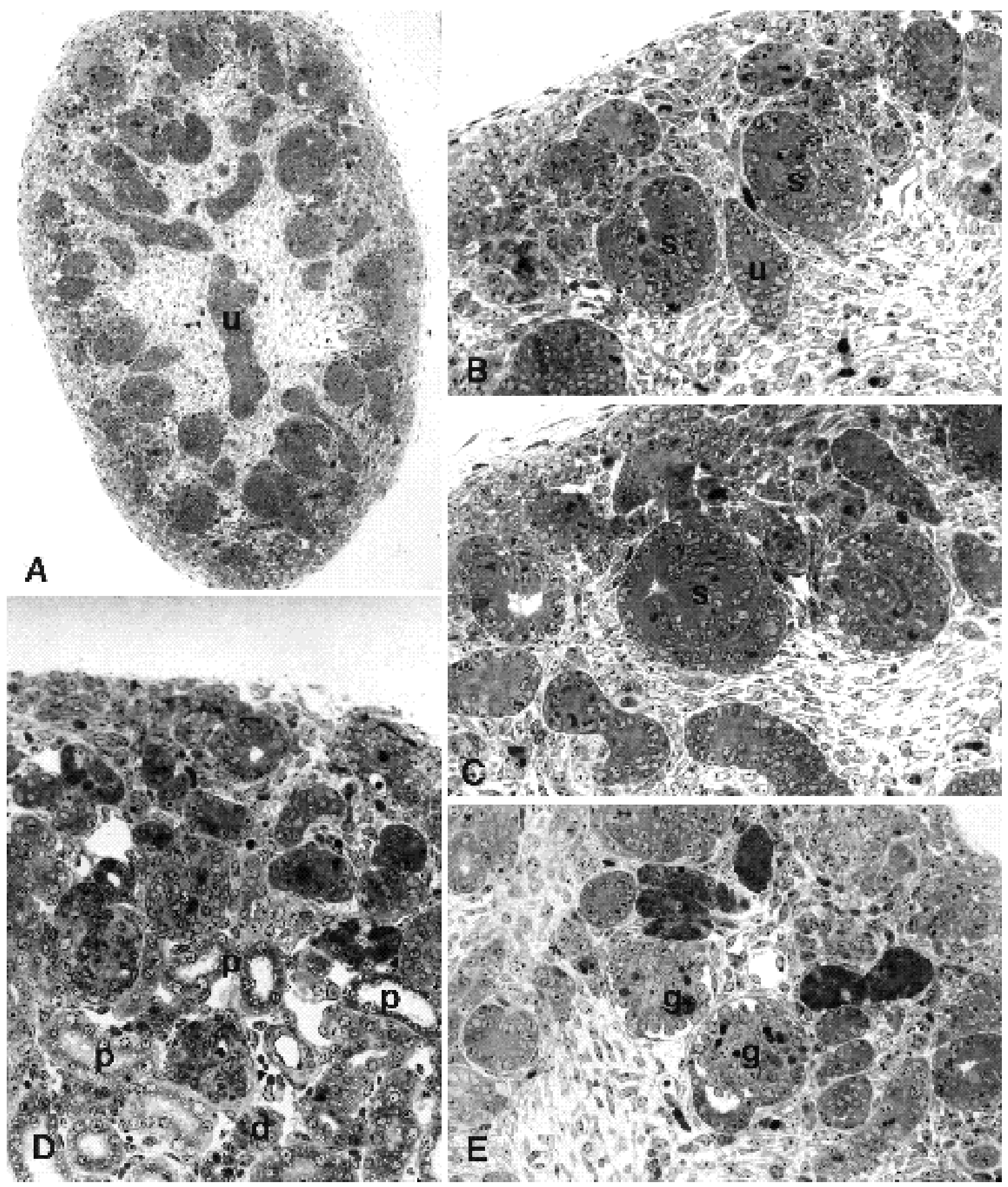

Fig. 2. Stages of development of the metanephric kidney. (A) A kidney of a 14-day-old mouse embryo. Low magnification showing several pretubular aggregates in the cortical zone and the ureter (u) in the centre. $(\times 120)$. (B and C) Higher magnifications of the cortical zone of a kidney of a 16-day-old mouse embryo showing early and later stages of S-shaped bodies (s). ( $\times 300)$. (D and E) Two views of a kidney of a 18-day-old mouse embryo showing maturing proximal (p) and distal (d) tubules and early glomeruli (g). (E, $\times 300 ; \mathrm{D}, \times 200)$.

Fig. 3. Immunohistochemical localization of $\alpha_{1}$ gap junction protein $(\mathrm{GJ})$ in the developing mouse and rat kidneys. (A) A section through a 14-day mouse embryonic kidney showing a subcortical ring of cells expressing the $\alpha_{1}$ GJ protein. ( $\times 75$ ). (B) Higher magnification of the subcortical zone illustrating a terminal branch of the ureter (u, arrow) and two mesenchyme-derived early S-shaped bodies (s) expressing the $\alpha_{1}$ GJ antigen predominantly in their lower crevice. $(\times 300)$. (C, D) Double immunofluorescence view of a late S-shaped body of a 17-day rat embryonic kidney stained with antibodies against $\alpha_{1}$ GJ antigen (C) and against podocalyxin visualizing the maturing podocytes $(\mathrm{p}, \mathrm{D})$. The GJ-protein becomes downregulated when the podocytes mature. $(\times 360)$. $(\mathrm{E}, \mathrm{F})$ Double immunofluorescence view of the cortex of a kidney from 20-day rat embryo stained as above. The $\alpha_{1}$ GJ protein is still expressed in the S-shaped bodies (s) and in the immature glomeruli $(\mathrm{g}, \mathrm{E})$, but not in the maturing podocytes expressing podocalyxin $(\mathrm{F})$. $(\times 200)$. 

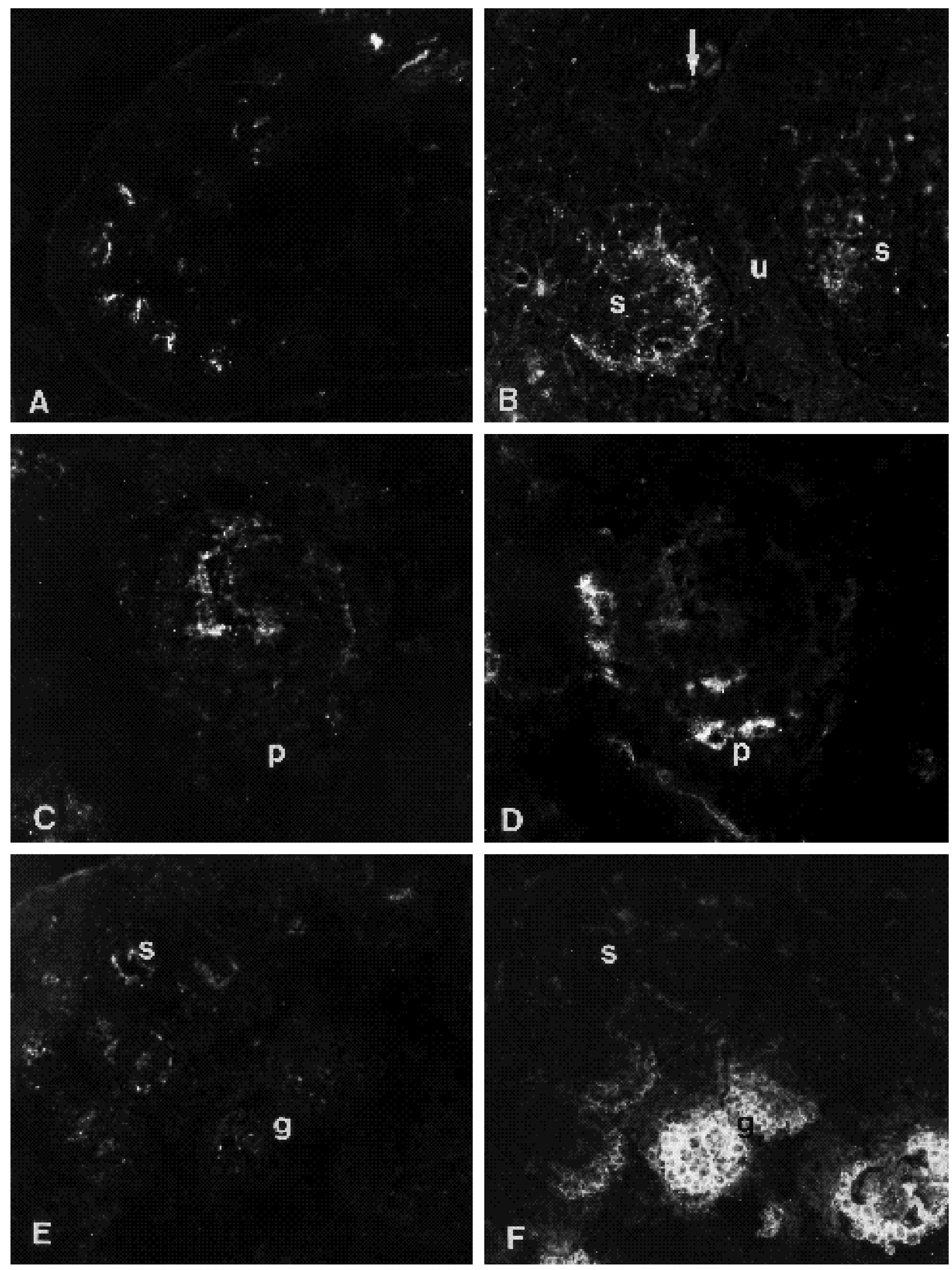


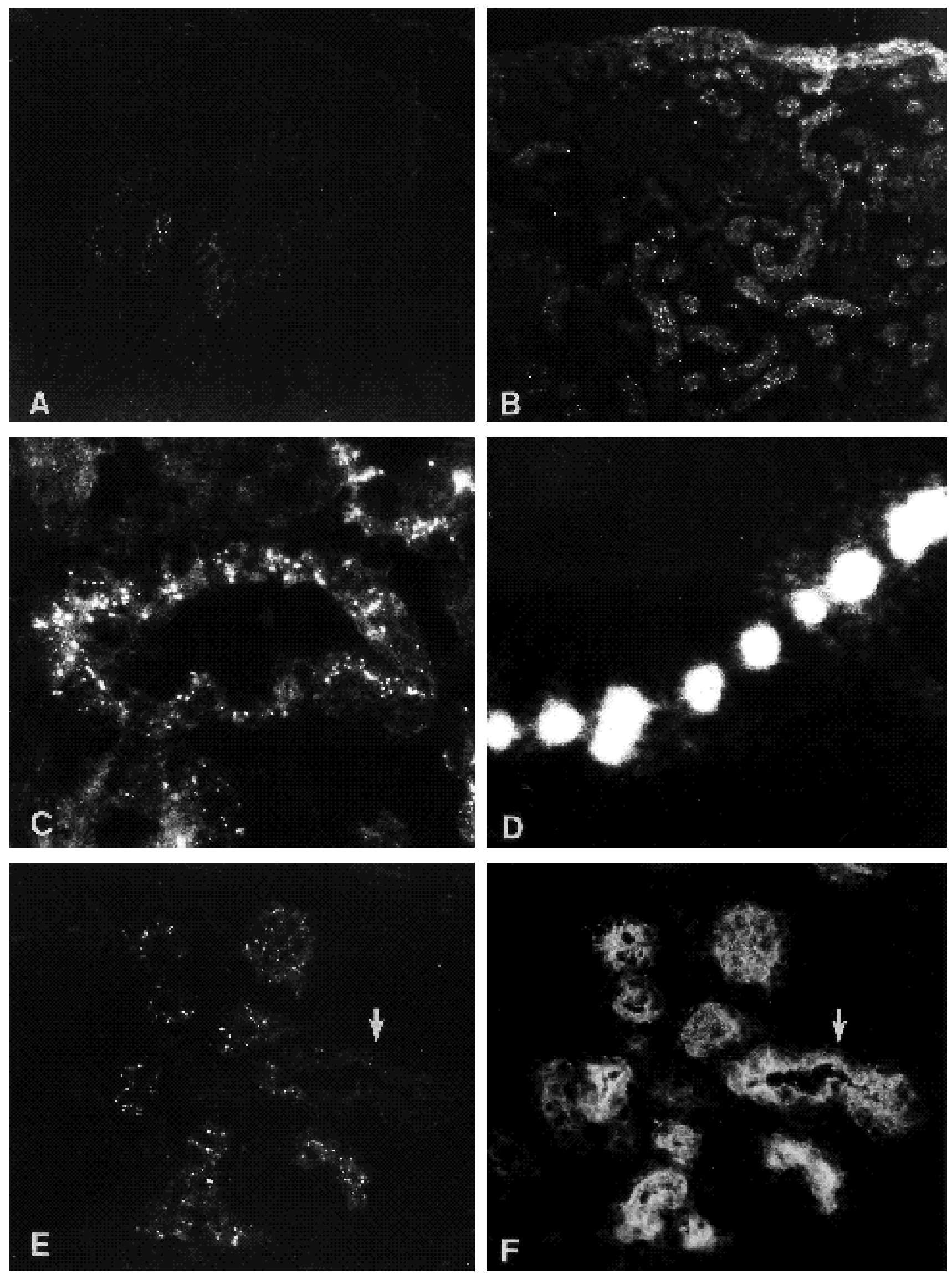


Fig. 4. Immunohistochemical localization of the $\beta_{2}$ GJ protein in the tubules of developing mouse and rat kidneys. (A) Small subcortical groups expressing the GJ antigen in the kidney of a 17-day mouse embryo. $(\times 120)$. (B) A similarly treated cortical region of kidney of a newborn mouse where a majority of the proximal tubules express $\beta_{2}$ GJ protein. $(\times 100)$. (C) A proximal tubule of a 17-day mouse embryonic kidney composed of $\beta_{2}$ GJpositive cells. ( $\times 500)$. (D) Confocal microscopy section through a $\beta_{2}$ GJ-positive tubule in a 17-day mouse embryonic kidney. $(\times 12$ 000). (E, F). Double immunofluorescent staining of $\beta_{2}$ GJ protein (E) and dipeptidylpeptidase IV (DPY) (F) of a section through a 20-day rat kidney. Note the tubular portions already expressing DPY, but not yet the gap junction protein (arrows). $(\times 350)$.

No $\beta_{2}$ antigen was detected in day 12 and day 15 kidneys. At day $17, \beta_{2}$ GJ protein was detected in only a few tubular cells in each section of kidney where dots of fluorescence were observed (Fig. 4). After day 17, more cells expressed this antigen, and it was abundant in the tubules of newborn and adult kidneys.

The cells expressing the $\beta_{2}$ GJ protein were seen only in those areas of the kidney that contained proximal tubules. The identification of the $\beta_{2}$-positive cells with proximal tubules was made by immunofluorescence. First, adjacent sections of 20-day embryonic mouse kidney were stained with antibodies to the $\beta_{2}$ GJ protein and to proximal tubule brush border antigen and antibodies to distal tubule TammHorsfall glycoprotein. These studies demonstrated that the $\beta_{2}$ GJ antigen was located specifically on the brush-borderpositive proximal tubule cells (data not shown). Second, double immunofluorescent staining of sections of 20-day rat embryonic kidney (Fig. 4E, F) localized the $\beta_{2}$ antigen only to those tubules that expressed dipeptidylpeptidase IV, a marker for proximal tubule cells. As the kidney matured, more proximal tubules in each section were positive for the $\beta_{2}$ antigen and, by two weeks after birth, all brush border antigen-positive tubules were also positive for the $\beta_{2}$ antigen. This suggests that, in the kidney, the $\beta_{2}$ GJ protein is a specialized product of the proximal tubule cells.

\section{Expression pattern of the $\beta_{l}$ GJ protein}

The $\beta_{1}$ antigen was expressed in the embryonic kidney in the same way as $\beta_{2}$ : it appeared late during organogenesis, around day 17 in the mouse, and became localized first in a subset of proximal tubules (Fig. 5A). Towards the end of kidney development, new $\beta_{1 \text {-positive tubules were }}$ detectable until most (if not all) proximal tubules expressed the antigen in the newborn kidney (Fig. 5B).

\section{Expression of the GJ proteins in experimentally induced nephric mesenchymes}

To explore further the appearance of the GJ antigens and their localization, we used the transfilter technique by which isolated kidney mesenchymes can be experimentally triggered to develop into advanced tubular structures (see Methods). In the rat, the uncommitted mesenchyme is dissected from 13-day embryos and brought into transfilter contact with a fragment of spinal cord. On day 4 after setting up the culture, the $\alpha_{1}$ GJ protein could be detected in many tubular structures (Fig. 6A-C). Immunostaining with the $\beta_{1}$ and $\beta_{2}$ GJ antigens yielded invariably negative results up to 7 days in vitro.

In the mouse, the uncommitted nephric mesenchyme is dissected from 11-day embryos and brought into contact with the inducer. We have previously shown that a short transfilter induction "pulse" of 24 to 28 hours is sufficient to program the mesenchyme into epithelial transformation and tubule formation (Wartiovaara et al., 1974; Saxén and Lehtonen, 1978). Using markers for the various segments of the secretory nephron, we have shown that all three main segments, the distal and proximal tubules and the glomerular podocytes, will differentiate after this pulse (Ekblom et al., 1980, 1981; Lehtonen et al., 1983). Here, however, a 22-hour induction was not long enough to trigger the $\alpha_{1}-\mathrm{GJ}$ antigen in the observed, cytokeratin-positive tubules, but an additional 26 hours of transfilter contact yielded positive tubules in mesenchymes subcultivated for 3 days (Fig. 6D). Interest-
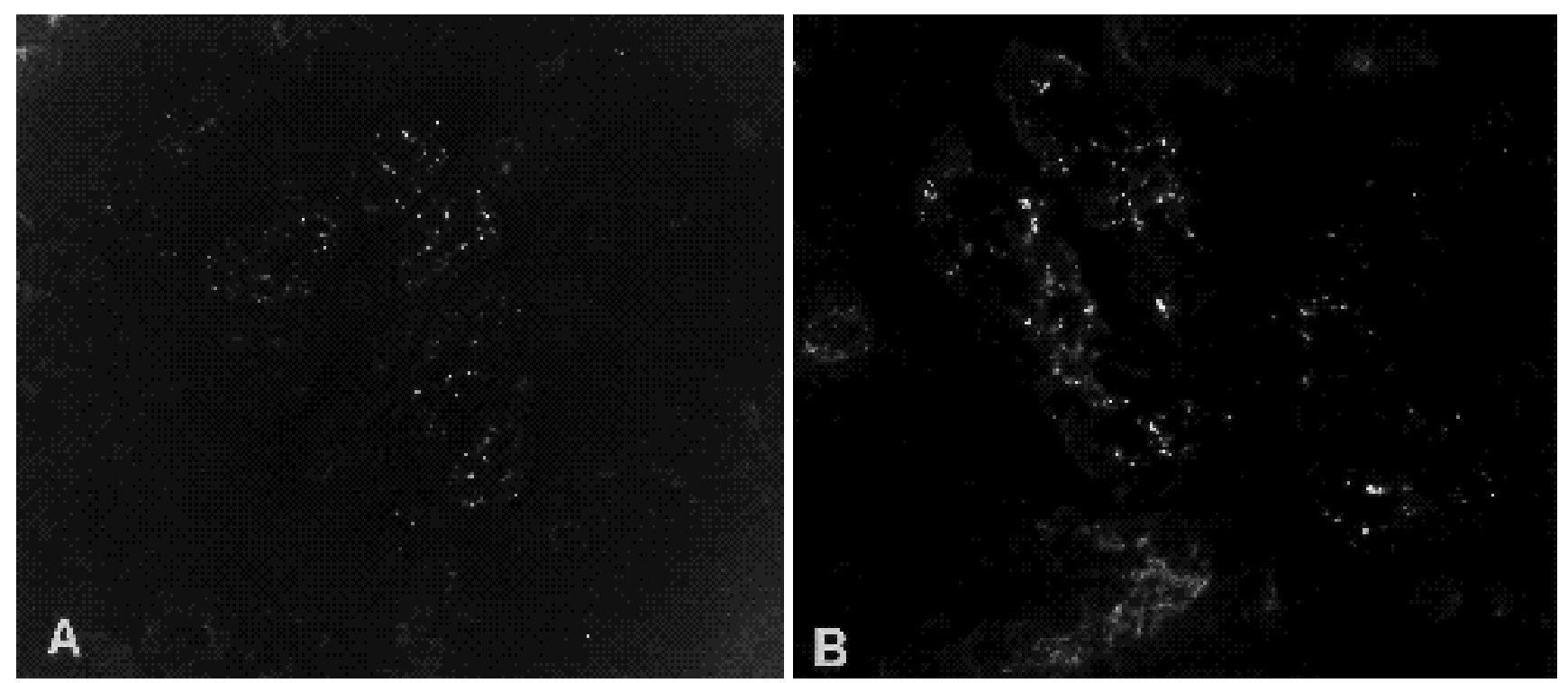

Fig. 5. Immunofluorescence localization of the $\beta_{1}$ GJ protein first expressed in some secretory tubules of a 17-day embryonic kidney (A) $(\times 260)$ and detected in the newborn kidney of the mouse $(B) .(\times 300)$. 

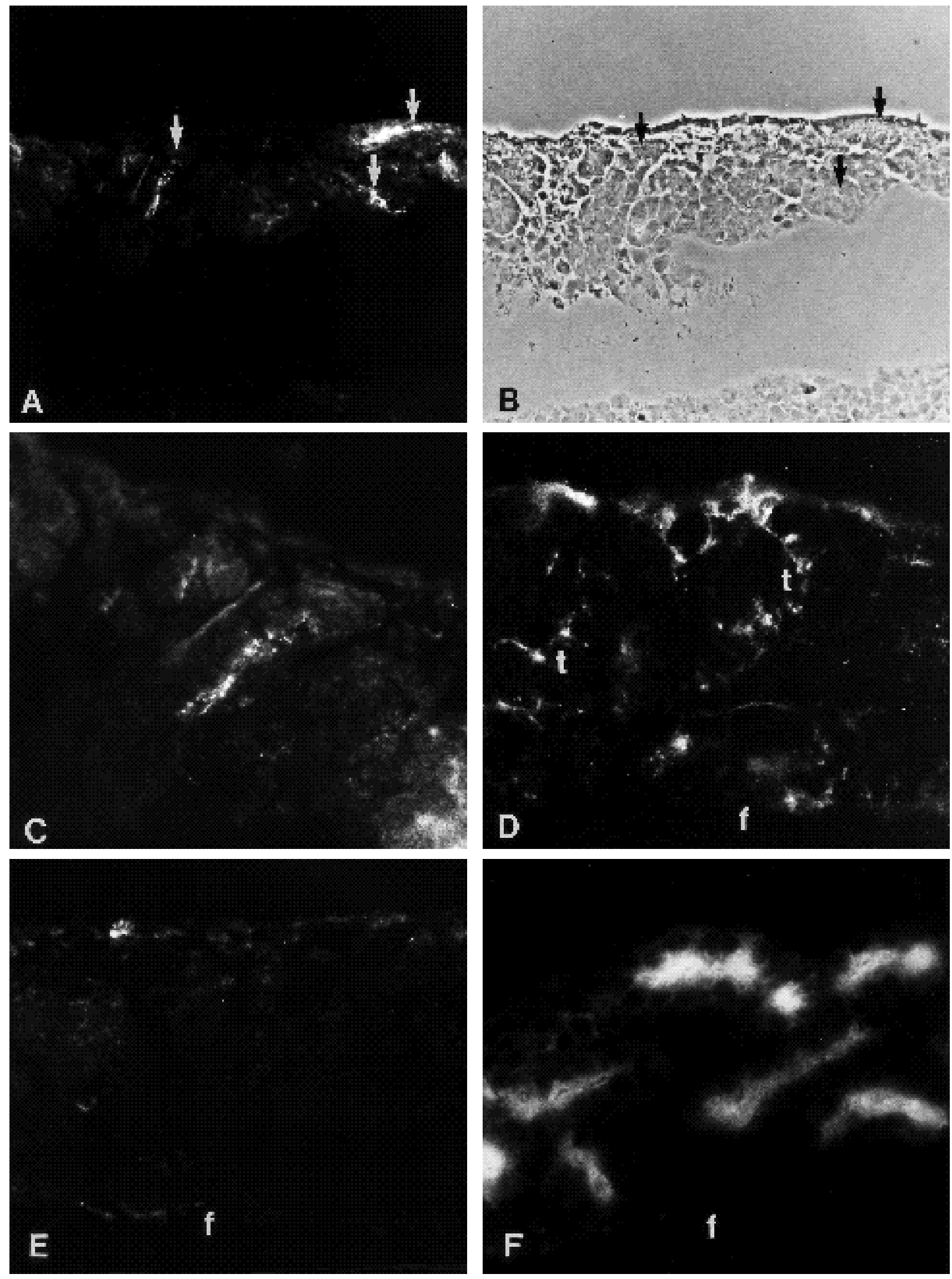
Fig. 6. Immunohistochemical demonstration of the expression of $\alpha_{1}$ gap junction protein in experimentally induced metanephric mesenchymes. (A) A mesenchyme from a 13-day rat embryo was cultured transfilter to the inductor for 4 days and then stained with an antibody to the $\alpha_{1}$ GJ protein (arrows). $(\times 200)$. (B) A phase contrast view of the same tubules (arrows) in the mesenchyme illustrated in (A). (×200). (C) Higher magnification of the tubule seen on the left in the above figures and stained with $\alpha_{1}$ GJ antibody. ( $\times 900)$. (D) Tubules (t) expressing the $\alpha_{1}$ GJ antigen in an 11-day mouse metanephric mesenchyme induced through a filter (f) for 48 hours and subcultivated for 72 hours. $(\times 750)$. (E and F) A transfilter-induced mouse metanephric mesenchyme cultivated for 7 days and stained with the $\alpha_{1}$ GJ antibody. The result of the immunostaining is negative $(\mathrm{E})(\times 720)$. A section similar to that in E stained with a brush-border antibody, reacting specifically with the proximal tubules $(F)(\times 720)$.

ingly, as in vivo, this expression was transient and no $\alpha_{1-\text { pos- }}$ itive cells were detected in mesenchymes cultivated for a total of 7 days.

As in the rat, immunostaining with the $\beta_{1}$ and $\beta_{2}$ GJ antibodies yielded invariably negative results (Fig. 6E) despite the presence of well- developed proximal tubules expressing the brush-border antigen (Fig. 6F).

\section{Discussion}

This study examined the expression of mRNA and protein from three gap junction (GJ) genes during murine kidney development. Two non-overlapping patterns of expression were observed. The mRNA for the $\alpha_{1}$ GJ protein was already prevalent in the mouse kidney by embryonic day 13, and it continued to be expressed throughout embryonic development. Immunofluorescence microscopy showed that this GJ protein was expressed as early as day 12 in the metanephric kidney, as also recently reported by Yancey et al. (1992). The $\alpha_{1}$ GJ protein becomes localized to the transient S-shaped bodies produced by the mesenchymal aggregates.

The expression of the mRNAs and antigens for both $\beta_{1}$ and $\beta_{2}$ GJ proteins follow similar patterns. By S1 nuclease protection assay, this mRNA is detected around day 17 of mouse development, and soon thereafter the protein can be localized to a subset of proximal tubules as verified with the brush border (mouse) and the dipeptidylpeptidase (rat) antigens. By birth, the kidney already expresses an adult pattern wherein all proximal tubules can be decorated by the two gap junction antibodies. This is consistent with the mRNA data, which provides evidence for an increased expression of the mRNAs after their initial appearance during late intrauterine development.

The different expression of the $\alpha$ and $\beta$ GJ proteins during nephrogenesis suggests that they have different functions. The transient expression of the $\alpha_{1}$ GJ protein in vivo coincides with a unique stage of development of the secretory nephron. At this stage, the primitive nephric vesicle undergoes a transformation into the S-shaped body, an event involving cleft formation and invagination followed by differential cytodifferentiation of the main segments (Jokelainen, 1963; Saxén and Wartiovaara, 1966). In the experimental in vitro model system, the appearance of the $\alpha_{1}$ GJ antigen coincides temporally with this crucial step of tubulogenesis although the shaping process remains incomplete. In such transfilter cultures where development was followed after a short induction pulse, the antigen was not expressed. This may lend further support to the morphogenetic role of the $\alpha_{1}$ GJ protein. Gossens and Unsworth (1972) have provided experimental evidence for a two-step process in tubule induction: an initial, epithelializing stimulus is followed by further interactions between the epithelium of the renal vesicle and the mesenchymal stroma leading to the shaping and coiling of the tubule. This second step might be impaired in our short-term induction pulse experiments in which the uninduced mesenchyme is soon lost in prolonged cultures. When the segments of the secretory nephron have segregated (in vivo and in vitro), the $\alpha_{1}$ GJ protein is downregulated. All of this suggests that the protein is involved in a specific stage of development, a suggestion consistent with many previous experimental results and observations on various systems. The findings in the kidney might be analogous to that described by Yancey et al. (1992) in the developing limb bud, where $\alpha_{1}$ GJ protein was seen to interconnect the polarizing cells within the apical ectodermal ridge rather than in the epithelial-mesenchymal interphase. The role of gap junctional communication during development has been shown in snail mesoderm formation (de Laat et al., 1980), in mammalian oocyte maturation (Anderson and Albertini, 1976; Gilula et al., 1978), in preimplantation mouse embryos (Lo and Gilula, 1979), and also suggested by observations on mutant Drosophila (Jurnisch et al., 1990). The transient expression of this GJ antigen and its appearance in the avascular, nonfunctional isolated mesenchymes in vitro speak against its functioning in the physiological processes of the newborn or mature kidney.

The expression of the mRNAs and antigens for the $\beta_{1}$ and $\beta_{2}$ GJ proteins follows a pattern different from that above, and it suggests a different function. Both appear rather late during development in vivo, and the proteins can be localized first to a subset of maturing proximal tubules. Around birth, apparently all proximal tubules express both $\beta$ proteins. In vitro, despite the prolonged culture period and the appearance of well-developed, non-functioning proximal tubules, the two $\beta$ GJ proteins were not detected. Both findings can be best interpreted as suggesting that the $\beta_{1}$ and $\beta_{2}$ GJ proteins are not directly involved in the process of tubulogenesis, but rather are connected to proximal tubule function.

The genes for these GJ proteins show different patterns of regulation. This has also been observed for other embryonic organs (Nishi et al., 1991). In the uterus, the day prior to parturition is characterized by a dramatic increase in $\alpha_{1}$ gene expression and a corresponding decrease in $\beta_{2}$ expression (Risek et al., 1990). However, in heart and liver, no changes in GJ protein gene transcription are seen around parturition. Thus, different GJ proteins can be regulated differently within the same organ, and the same GJ gene can be regulated differently in different organs in the same organism.

This study of GJ proteins and their transcripts demonstrates that different GJ proteins are utilized in different portions of the renal nephron. As a biological model, the developing kidney offers a good opportunity to analyze the formation of physiological compartments during the development of a complex mammalian organ. The major aspects of renal development are well characterized, and the nephron 
forms an array of distinct anatomical and physiological compartments. The formation of these physiological units may be structured by GJs which are used to compartmentalize information and to inform cells of their neighbors.

We wish to thank Ms Anja Tuomi, Ms Birgitta Tjäder and Ms Ulla Kiiski for their excellent assistance in the isolation, culturing and staining of the embryonic organs. This work was supported by a grant from the Sigrid Jusélius Foundation and NSF grant INT8922469 (S.G.), grants from the University of Helsinki and the Medical Research Council of the Academy of Finland (E. L.) and by NIH grants GM 37904 (N. B. G.), GM 37907 (N. B. G. and N. M. K.), and EY O6884 (N. M. K).

\section{References}

Anderson, E. and Albertini, D. F. (1976). Gap junctions between the oocyte and companion follicle cells in the mammalian ovary. J. Cell Biol. 71, 680-686.

Bacallao, R., Anthony C., Dotti, C., Karsenti, E., Stelzer, E. H. K. and Simons, K. (1989). The subcellular organization of Madin-Darby canine kidney cells during the formation of a polarized epithelium. $J$. Cell Biol. 109, 2817-2832.

Bennett, M. V. L. and Goodenough, D. A. (1978). Gap junctions, electrotonic coupling, and intercellular communication. Neurosci. Res. Prog. Bull. 16, 373-486.

Beyer, E. C., Paul, D. L. and Goodenough, D. A. (1987). Molecular cloning of cDNA for connexin 43, a gap junction protein from rat heart. J. Cell Biol. 105, 2621-2629.

Beyer, E. C., Kistler J., Paul, D. L. and Goodenough, D. A. (1989). Antisera directed against connexin 43 peptides react with a $43-\mathrm{kD}$ protein localized to gap junctions in myocardium and other tissues. $J$. Cell Biol. 108, 595-605.

Daniel, E. E. (1987). Gap junctions in smooth muscle. In Cell-to-Cell Communication (ed. W. C. De Mello), pp. 149-185. New York City: Plenum Publishing Company.

Davis, L. G., Dibner, M. D. and Batlery, J. F. (1986). Methods in Molecular Biology, Elsevier, New York City.

Dawnay, A., McLean, C. and Cattell, W. R. (1980). The development of a radioimmunoassay for Tamm-Horsfall glycoprotein in serum. Biochem. J. 185, 679-687.

Dreifuss, J. J., Girardier, C. and Forsmann, W. G. (1966). Etude de la propagation de l'excitation dans le verteicule de rat au moyen de solutions hypertoniques. Plugers Arch. 292, 13-33.

Ekblom, P., Miettinen, A. and Saxén, L. (1980). Induction of brush border antigens of the proximal tubule in the developing kidney. Dev. Biol. 74, 263-274.

Ekblom, P., Miettinen, A., Virtanen, I., Wahlström, T., Dawnay, A. and Saxén, L. (1981). In vitro segregation of the metanephric nephron. Dev. Biol. 84, 88-95.

Fraser, S. E., Green, C. R., Bode, H. R. and Gilula, N. B. (1987). Selective disruption of gap junctional communication interferes with a patterning process in Hydra. Science (Wash., DC) 237, 49-55.

Furshpan, E. J. and Potter, D. D. (1968). Low-resistance junctions between cells in embryos and tissue culture. In Current Topics in Developmental Biology (ed. A. A. Moscona and A. Monroy), Vol. 3, pp 95-127. New York City: Academic Press.

Gilula, N. B., Epstein, M. L. and Beers, W. H. (1978). Cell-to-cell communication and ovulation. A study of the cumulus-oocyte complex. J. Cell Biol. 78, 58-75.

Gilula, N. B., Reeves, O. R. and Steinbach, A. (1972). Metabolic coupling, ionic coupling, and cell contacts. Nature 235, 262-265.

Goodenough, D. A., Paul D. L. and Jesaitis, L. A. (1988). Topological distribution of two connexin 32 antigenic sites in intact and split rodent hepatocyte gap junctions. J. Cell Biol. 107, 1817-1824.

Gossens, C. L. and Unsworth, B. R. (1972). Evidence for a two-step mechanism operating during in vitro mouse kidney tubulogenesis. $J$. Embryol. Exp. Morphol. 28, 615-631.

Grobstein, C. (1956). Trans-filter induction of tubules in mouse metanephrogenic mesenchyme. Exp. Cell Res. 10, 424-440.

Guthrie, S. C. and Gilula, N. B. (1989). Gap junctional communication and development. TINS 12, 12-16.
Hertzberg, E. L., Disher, R. M., Tiller, A. A., Zhou, Y. and Cook, R. G. (1988). Topology of the $\mathrm{M}_{\mathrm{r}} 27,000$ liver gap junction protein. $J$. Biol. Chem. 263, 19105-19111.

Hoh, J. H., John, S. A. and Revel, J.-P. (1991). Molecular cloning and characterization of a new member of the gap junction gene family, Connexin-31. J. Biol. Chem. 266, 6524-6531.

Jokelainen, P. (1963). An electron microscopic study of the early development of the rat metanephric nephron. Acta Anat. Suppl. 47, 173.

Jursnich, V. A., Fraser, S. E., Held L. I., Jr., Ryerse, J. and Bryant, P. J. (1990). Defective gap-junctional communication associated with imaginal disc overgrowth and degeneration caused by mutations of the dco gene in Drosophila. Dev. Biol. 140, 413-429.

Kalimi, G. H. and Lo, C. W. (1988). Communication compartments in the gastrulating mouse embryo. J. Cell Biol. 107, 241-255.

Kalimi, G. H. and Lo, C. W. (1989). Gap junctional communication in the extraembryonic tissues of the gastrulating mouse embryo. J. Cell Biol. 109, 3015-3026.

Kistler, J., Christie, D. and Bullivant, S. (1988). Homologies between gap junction proteins in lens, heart, and liver. Nature 331, 721-723.

Klein, G., Langegger, M., Goridis, C. and Ekblom, P. (1988). Neural cell adhesion molecules during embryonic induction and development of the kidney. Development 102, 749-761.

Kumar, N. M. and Gilula, N. B. (1986). Cloning and characterization of human and rat liver cDNAs coding for a gap junction protein. $J$. Cell Biol. 103, 767-776.

de Laat, S. W., Tertoelen, L. G. J., Dorresteijn, A. W. C. and van der Biggelar, J. A. N. (1980). Intercellular communication patterns are involved in cell determination during early molluscan development. Nature 287, 546-548.

Lee, S., Gilula N. B. and Warner, A. E. (1987). Gap junction communication and compaction during preimplantation stages of mouse development. Cell 51, 851-860.

Lehtonen, E., Jalanko, H., Laitinen, L., Miettinen, A., Ekblom, P. and Saxén, L. (1983). Differentiation of metanephric tubules following a short transfilter induction pulse. Roux Arch. Dev. Biol. 192, 145-151.

Lo, C. W. and Gilula, N. B. (1979). Gap junctional communication in the preimplantation mouse embryo. Cell 18, 339-409.

Loewenstein, W. R. (1981). Junctional intercellular communication: the cell-to-cell membrane channel. Physiol. Rev. 61, 829-913.

Miettinen, H. and Linder, A. (1976). Membrane antigens shared by renal proximal tubules and other epithelia associated with absorption and excretion. Clin. Exp. Immunol. 23, 568-577.

Miettinen, A., Dekan, G. and Farquhar, M. G. (1990). Monoclonal antibodies against membrane proteins of the rat glomerulus. Immunochemical specificity and immunofluorescence distribution of the antigens. Amer. J. Pathol. 137, 929-944.

Milks, L. C., Kumar, N. M., Houghten, R., Unwin, N. and Gilula, N. B. (1988). Topology of the $32 \mathrm{kd}$ liver gap junction protein determined by site-directed antibody localizations. EMBO J. 7, 2967-2975.

Nicholson, B. J. and Zhang, J. T. (1988). Multiple protein components in a single gap junction: cloning of a second hepatic gap junction protein (MW 21,000). Mol. Cell Biol. 7, 207-218.

Nishi, M., Kumar, N. M. and Gilula, N. B. (1991). Developmental regulation of gap junction gene expression during mouse embryonic development. Dev. Biol. 146, 117-130.

Paul, D. L. (1986). Molecular cloning of cDNA for rat liver gap junction protein. J. Cell Biol. 103, 123-134.

Risek, B., Guthrie, S., Kumar, N. and Gilula, N. B. (1990). Modulation of gap junction transcript and protein expression during pregnancy in the rat. J. Cell Biol. 110, 269-282.

Saxén, L. (1987). Organogenesis of the Kidney. Cambridge: Cambridge University Press.

Saxén, L. and Lehtonen, E. (1978). Transfilter induction of kidney tubules as a function of the extent and duration of intercellular contacts. J. Embryol. Exp. Morphol. 47, 97-109.

Saxén, L. and Lehtonen, E. (1987). Embryonic kidney in organ culture. Differentiation 36, 2 -11.

Saxén, L. and Wartiovaara, J. (1966). Cell contact and cell adhesion during tissue organization. Int. J. Cancer 1, 271-290.

Schnabel, E., Dekan, G., Miettinen, A. and Farquhar, M. G. (1989). Biogenesis of podocalyxin - the major glomerular sialoglycoprotein - in the newborn rat kidney. Eur. J. Cell Biol. 48, 313-326.

Sikri, K. L., Foster, C. L., Bloomfield, F. L. and Marshall, R. D. 
(1979). Localization by immunofluorescence and light- and electronmicroscopic immunoperoxidase techniques of Tamm-Horsfall glycoprotein in adult hamster kidney. Biochem. J. 181, 525-532.

Stelzer, E. H. K., Stricker, R., Pick, R., Storz, C. and Hänninen, P. (1989). Confocal fluorescence microscopes for biological research. In Scanning Imagings (ed. T. Wilson), pp. 146-151. Bellingham: Society of Photo-optical Instrumentation and Engineering.

Warner, A. E. (1973). The electrical properties of the ectoderm in the amphibian embryo during induction and early development of the nervous system. J. Physiol. 235, 267-286.

Warner, A. E., Guthrie, S. C. and Gilula, N. B. (1984). Antibodies to gap junctional protein selectively disrupt junctional communication in the early amphibian embryo. Nature 311, 127-131.

Wartiovaara, J., Nordling, S., Lehtonen, E. and Saxén, L. (1974) Transfilter induction of kidney tubules: correlation with cytoplasmic penetration into Nuclepore filters. J. Embryol. Exp. Morphol. 31, 667682.
Weir, M.P. and Lo, C. W. (1982). Gap junction communication compartments in the Drosophila wing disc. Proc. Natl Acad. Sci. (USA) 79, 3232-3235.

Yancey, S. B., Biswal, S. and Revel J.-P. (1992). Spatial and temporal patterns of distribution of the gap junction protein connexin43 during mouse gastrulation and organogenesis. Development 114, 203-212.

Yancey, S. B., John, S., Lal, R., Austin, B. and Revel, J.-P. (1989). The 43-kD polypeptide of heart gap junctions: immunolocalization (I), topology (II), and functional domains (III). J. Cell Biol. 108, 22412254.

Zimmer, P. B., Green, C. R., Evans, H. W. and Gilula, N. B. (1987). Topological analysis of the major protein in isolated intact rat liver gap junctions and gap junction-derived single membrane structures. J. Biol. Chem. 262, 7751-7763. 